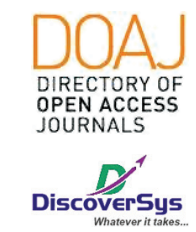

Published by DiscoverSys

\section{Steven-Johnson Syndrome associated with anti-tuberculosis drugs: A case reports}

\author{
I Gusti Ayu Risma Pramita, ${ }^{1 *}$ Tjokorda Dalem Pemayun²
}

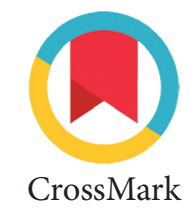

CrossMark

\title{
ABSTRACT
}

Introduction: Steven-Johnson syndrome (SJS) is an acute reaction to the skin and mucous membranes that is characterised by damage and flaking of the skin, accompanied by pain and can cause death. Treatment with anti-TB drugs sometimes results in side effects including SJS as one of the skin rash reaction and liver dysfunction. Steven-Johnson syndrome incidence and mortality due to anti-TB is quite rate and here we present a case with SJS and some other drugs side effect symptoms who passed away on the ninth day of treatment. Case description: A 53-year-old woman admitted to our emergency department with dyspnea, fatigue, erosion on oral mucosa, and erythema appears in the whole body accompanied by itch since two weeks ago, she also has yellowish sclera. She is in ongoing therapy of anti-tuberculosis drugs. History of hepatitis $B$, on admission there was marked elevation of leukocyte and liver function test (AST and ALT). Systemic corticosteroid was given as characterised therapy with topical steroid and antibiotics regimen for maculopapular rash.

Conclusion: SJS is an emergency requiring high attention and intensive care evaluation with administration of intravenous systemic steroids as primary immunosuppressive therapy.
${ }^{1}$ Medical Doctor, Wangaya General Hospital, Bali-Indonesia

${ }^{2}$ Dermatology and Venereology Department, Wangaya General Hospital, Denpasar, Bali-Indonesia

*Correspondence to: I Gusti Ayu Risma Pramita, Medical Doctor, Wangaya General Hospital, Bali-Indonesia

igustiayurisma@gmail.com

Received: 2019-09-24 Accepted: 2020-05-30 Published: 2020-08-01

Keywords: steven-johnson syndrome, risk, allergy, immunology, rash.

Cite This Article: Pramita, I.G.A.R., Pemayun, T.D. 2020. Steven-Johnson Syndrome associated with anti-tuberculosis drugs: A case reports. Intisari Sains Medis 11(2): 610-612. D0I: 10.15562/ism.v11i2.628

\section{INTRODUCTION}

Stevens-Johnson Syndrome (SJS) incidence rates are estimated at 2 to 7 cases per 1 million people per year. This reaction can occur at any age, but the incidence increases above the 4th decade and is more common in women. The mortality rate for this disease is said to be up to $10 \%$. Some things that affect the severity of this disease, including older age, other diseases that accompany, and the extent of the surface of the body involved. ${ }^{1,2}$

SJS is an acute reaction to the skin and mucous membranes characterised by damage and flaking of the skin, accompanied by pain and can cause death. This disease was first discovered in 1922 by a paediatrician after diagnosing a child with a disorder caused by a drug reaction. SJS usually starts within 8 days after drug administration (range 4-30 days). In some cases giving a quick reaction within a few hours. SJS reactions are usually caused by exposure to the same drug. ${ }^{2}$

Tuberculosis (TB) is the ninth leading cause of death worldwide and most of the estimated number of incident cases in 2016 occurred in the WHO-SouthEast Asia Region (45\%). The top five countries, with $56 \%$ of estimated cases were India, Indonesia, China, Philippines, and Pakistan. Globally, the TB mortality rate is falling at about $3 \%$ per year. ${ }^{1}$

Tuberculosis is an infectious disease caused by Mycobacterium tuberculosis and remains endemic in Asia, in particular, China and India. ${ }^{2}$ Progression in disease control emerges since 1882 and antituberculosis drug found in 1943 started with Streptomycin. ${ }^{3}$ Treatment with anti-TB drugs sometimes results in side effects for patients, including drug reactions, both allergic and non-allergic. ${ }^{4}$ The adverse reactions mainly include drug-induced liver injury, gastrointestinal reactions, and skin rash. ${ }^{5}$

The most common adverse reaction caused by the first-line anti-tuberculosis drugs is mild liver dysfunction, while severe liver toxic effects including liver failure or even death are very rare. ${ }^{6}$ Skin rash is the second leading adverse reaction and drug eruptions resulting from these medications are still a major obstacle to treatment. ${ }^{5,7}$ Here, we present a mortality case induced by anti-TB side effect.

\section{CASE REPORT}

A 53-year-old woman admitted to our hospital with dyspnea and fatigue. Erythema appears in the whole body accompanied by itch since two weeks ago. She also has yellowish sclera. She starts anti-TB treatment two months ago consist of rifampicin, pyrazinamide, and isoniazid. She also begins hypertension treatment with amlodipine. On admission, the physical examination revealed extensive areas of maculopapular with pruritus at the skin of the trunk and extremities. Erosion appears in the oral mucosa (Figure 1). There were no liver enlargements, only yellowish sclera that direct us to liver 


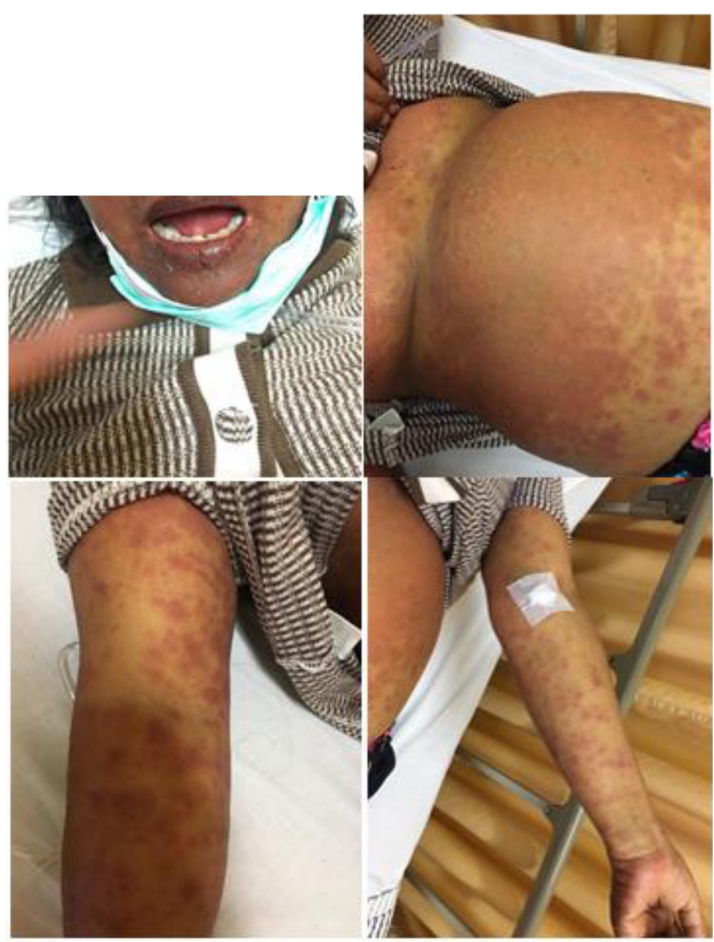

Figure 1 The dermatologic condition on the first day of admission

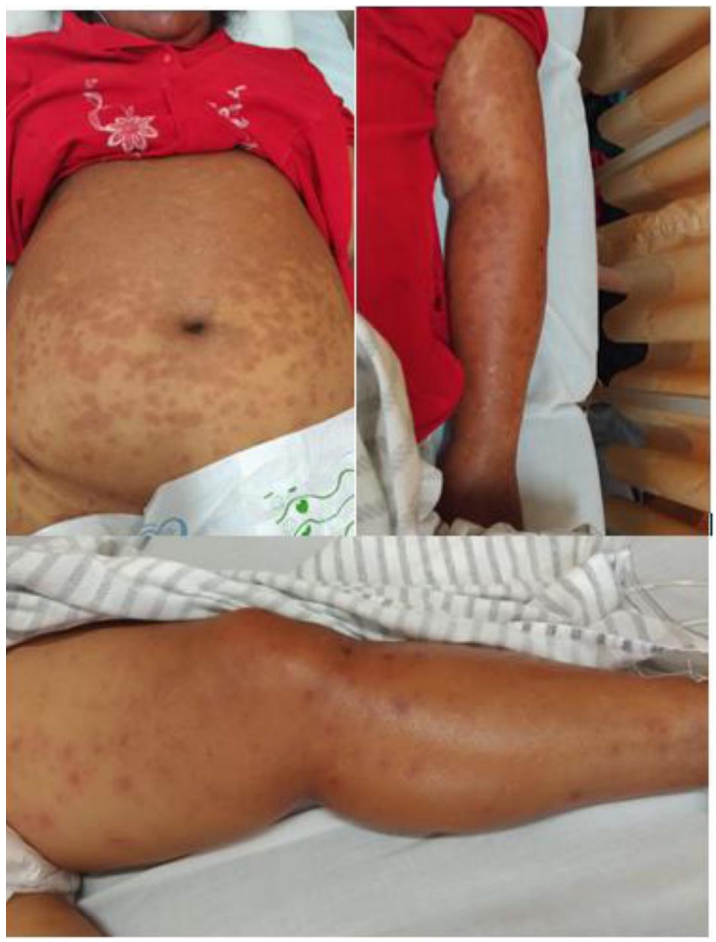

Figure 2 Dermatologic condition on the day before the patient passed away

disorder. The blood pressure was 100/60 $\mathrm{mmHg}$, pulse 80 beats/minute, respiration rate 22 times/ minute, and temperature $36^{\circ} \mathrm{C}$. Complete blood count shows leukocytosis (11.8) slightly with monocyte and eosinophil predominance $(10.7 \%$ and 5.0\%). Liver function test shows ALT 283, AST
3.451, total bilirubin 11.8 and direct bilirubin 11.5. That result shows liver dysfunction and also there was hypokalemia, hyponatremia, and hypochlorite (3.1, 111, 76 respectively). Initially, the patient was diagnosed with maculopapular drug eruption caused by anti-TB treatment or amlodipine, drug-induced hepatitis, hyponatremia, hypokalemia, and TB on treatment. After admission, all the anti-TB drugs and amlodipine were stopped, but the skin rash and liver damages were not improved.

Leukocytosis and liver function is getting worse in $4^{\text {th }}$ day of treatment. We also found that the patient is having hepatitis B with positive HbsAg and reassess with Steven-Johnson syndrome - Toxic Epidermal Necrolysis (SJS-TEN), a decrease of consciousness suspect caused by septic encephalopathy with a differential diagnosis with encephalopathy hepatic, lung TB on treatment, chronic liver disease, hepatitis $\mathrm{B}$, suspect pneumonia accompanied with sepsis. Fluid management was given concomitant with norepinephrine and dobutamine. Methylprednisolone intravenous and desoxymethasone plus gentamicin cream were given to control the skin reaction. Triamcinolone acetonide ointment was given to treat lesion in the oral mucosa. She also receives levofloxacin and gentamycin injection to control the infection. Skin lesion on day $8^{\text {th }}$ day can be seen in figure 2 . The patient was apnea periodically and receives ventilator management in ICU on the $9^{\text {th }}$ day. Soon after admitted to ICU the patient passed away.

\section{DISCUSSION}

Non-immediate reactions are much more common than the immediate reaction to anti-TB drugs. These include maculopapular eruption, lichenoid drug eruptions, haematological reactions, hepatitis, SJS and TEN. ${ }^{8}$ The duration between drug intake and first onset of symptom in SJS/TEN ranges between a few hours and 45 days. ${ }^{9}$ As in this case, our patient starts the symptoms around 40 days after drug consumption.

The global incidence of SJS/TEN range from 1.2 to 6 patients per million per year for SJS, TEN 0.4 to 1.2 , and SJS/TEN as a reaction that specific to anti-TB drug is quite rare. ${ }^{10,11}$ Hypersensitivity reaction to anti-TB has been reported in 4 to $5 \%$ of the general population and SJS secondary to anti-TB only occurs in $0.96 \%$ of cases. ${ }^{12,13}$ Mortality for SJS varies from 3 to $10 \%$ and for TEN 20 to $40 \% .^{12}$ Previous studies have already demonstrated that skin rash caused by first-line anti-TB drugs is associated with genetic variations of CYP2C19 and CYP2C9 genes. ${ }^{14,15} \mathrm{~A}$ recent study in Korea showed that tuberculosis patients with ABCC2 gene haplotype or polymorphism were with a high risk of developing a skin rash after the intake of first-line anti-TB. ${ }^{16}$ 
Drug-induced liver injuries caused by anti-TB drugs are very common. In the present study, the patient was found with severe skin rash and liver dysfunction within 40 days after the intake of anti-TB drugs (rifampicin, pyrazinamide, and isoniazid). Isoniazid is an essential component in the universal accepted first-line anti TB strategies. The ALT level of the patients will be increased to $\geq 5$ times the upper limit of the normal range at 2-3 months after the intake of isoniazid. ${ }^{5}$ In this case, the ALT level was increased 8 times above the upper limit. Isoniazid is an essential component in first-line anti-TB and has been considered as druginduced liver toxicity. The NAT2 in the liver of the patients could metabolize the isoniazid into acetyl isoniazid, which could be oxidised by CYP4502E1 into liver toxic intermediate, damage the polymorphism, which could change the function of NAT27. NAT2 acetylation gene polymorphism includes fast, moderate, and slow metabolism type, while slow metabolism type could induce the development of liver toxicity, which will affect the efficacies of anti-tuberculosis treatment and the occurrence of the adverse effects. ${ }^{17}$ The incidence of drug-induced liver injury is $51.2 \%$ in patients with slow acetylation genes after intake isoniazid, while the incidence in the ones with fast acetylation genes is only $25.2 \% .{ }^{18}$

Pyrazinamide and ethambutol are two drugs commonly used in combination with isoniazid in the first-line anti-TB. The adverse effect of ethambutol is mainly optic nerve damages, while liver injury is very rare. Pyrazinamide could cause arthralgia, appetite decrease, fever, liver injury and skin rash in some case. ${ }^{19}$

\section{CONCLUSION}

First-line anti-TB drugs are key to eradicate the infection. Moreover, reaction to an anti-TB drug such as SJS/TEN and also liver toxicity have a varied incident and the high mortality caused by those reactions should become a concern for the physician. Cautions in using any agent especially antimicrobial which known as a significant cause in SJS/TEN and also general check-up before starting any medication should be highlighted.

\section{CONFLICT OF INTEREST}

The author declares there is no conflict of interest regarding the publication of current report.

\section{ETHICAL ASPECT}

The patient had received inform consent regarding the publication of their respective photograph in journal article.

\section{REFERENCES}

1. WHO. Global tuberculosis report 2017, France: World Health Organization; 2017.

2. Glaziou P, Floyd K, Raviglione MC. Global epidemiology of tuberculosis. Semin Respir Crit Care Med. 2018;39(3):271-285.

3. Tomioka H, Namba K. Development of antituberculous drugs: current status and future prospects. Kekkaku. 2006;81(12):753-74.

4. Amanda G, Nurwidya F, Isbaniyah F. Pulmonary tuberculosis with fixed drug eruption to all first-line antituberculosis drugs. Respir Case Rep. 2017;6(2):82-85.

5. Guo D, Yu M, Hu Y, Wu X. Severe skin rash and liver toxic effects caused by first-line anti-tuberculosis drugs: a case report. Int J Complement Alt Med. 2017;5(4):1-4.

6. Tostmann A. et al. Antituberculosis drug-induced hepatotoxicity: concise up-to-date review. J Gastroenterol Hepatol. 2008;23(2):192-202.

7. Kato Y, Sato Y, Tsuboi R. Immediate type hypersensitivity and late phase reaction occurred consecutively in a patient receiving ethambutol and levofloxacin. Allergy Asthma Clin Immunol. 2018;14(13):1-4.

8. Thong BY, et al. A retrospective study on sequential desensitization-rechallenge for antituberculosis drug allergy. Asia Pacific Allergy. 2014;4:156-163.

9. Sanmarkan AD, Sori T, Thappa DM, Jaisankar TJ. Retrospective analysis of Steven-Johnson syndrome and toxic epidermal necrolysis over a period of 10 years. Indian J Dermatol. 2001;56(1):25-29.

10. Wolkenstein P, Revuz J. Drug-induced severe skin reactions. Incidence, management and prevention. Drug Saf. 1995;13(1):56-68.

11. Lihite RJ. et al. A study on drug induced Steven-Johnson syndrome (SJS), toxic epidermal necrolysis (TEN) and SJSTEN overlap in a tertiary care hospital of Northeast India. J Young Pharm. 2016;8(2):149-153.

12. Mokenhaupt M, Schopf E. Epidemiology of druginduced severe skin reactions. Semin Cutan Med Surg. 1996;15(4):236-243.

13. Velazquez G, Ramirez E, Juarez E, Cicero R. Sindrome de Stevens Johnson relacionado con tratamiento antituberculoso. Enf Infec Y Microbiol. 1999;19(4):187-191.

14. Kim SH, et al. GSTT1 and GSTM1 null mutations and adverse reactions induced by antituberculosis drugs in Koreans. Tuberculosis (Edinb). 2019;90(1):39-43.

15. Kim SH, Jee YK, Lee JH, Lee BH. ABCC2 haplotype is associated with abtituberculosis drug-induced maculopapular eruption. Allergy Asthma Immunol Res. 2011;4(6):362-366.

16. Kim SH, et al. NAY2, CYP2C9, CYP2C19, and CYP2E1 genetic polymorphisms in anti-TB drug-induced maculopapular eruption. Eur J Clin Pharmacol. 2011;67(2):121-127.

17. Santos NPC, et al. N-acetyl transferase 2 and cytochrome P450 2E1 genes and isoniazid-induced hepatotoxicity in Brazilian patients. Int J Tuberc Lung Dis. 2013;17(6):499-504.

18. Boses PD, Sarma MP, Medhi S. Role of polymorphic N-acetyltransferase2 and cytochrome P4502E1 gene in antituberculosis treatment-induced hepatitis. J Gastroenterol Hepatol. 2011;26(2):312-318.

19. Azuma J. et al. NAT2 genotype guided regimen reduces isoniazid-induced liver injury and early treatment failure in the 6-month four-drug standard treatment of tuberculosis: a randomized controlled trial for pharmacogenetics-based therapy. Eur J Clin Pharmacol. 2013;69(5):1091-1101.

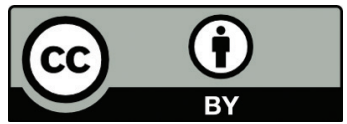

This work is licensed under a Creative Commons Attribution 